\title{
MELHORAMENTO DO TRIGO. XI. ESTUDO GENÉTICO DA TOLERÂNCIA À TOXICIDADE DE FERRO (')
}

\author{
CARLOS EDUARDO DE OLIVEIRA CAMARGO $\left({ }^{2,3}\right)$
}

\begin{abstract}
RESUMO
O cultivar Siete Cerros, tolerante, e o BH-1146, sensível à toxicidade de ferro, foram cruzados, sendo as sementes dos pais e dos cruzamentos em geração $F_{2}$ cultivadas em soluçōes nutritivas arejadas contendo 0,$56 ; 5$ e $10 \mathrm{mg} /$ litro de $\mathrm{Fe}$ em pH 4,0 e temperatura de $27 \pm 1^{\circ} \mathrm{C}$. O comprimento das raízes primárias centrais dos genótipos estudados, após dez dias de cultivo em soluções nutritivas contendo diferentes concentrações de ferro, serviu de base para avaliar a tolerância a esse elemento. Verificou-se que os genes existentes no 'Siete Cerros', responsáveis pela tolerância a $10 \mathrm{mg} /$ litro de ferro nas soluções, apresentaram um comportamento parcialmente dominante, e os genes encontrados em 'BH-1146', um comportamento parcialmente recessivo. Os valores da herdabilidade em sentido amplo para a tolerância à toxicidade de ferro, expressa na capacidade de crescimento das raízes das plântulas de trigo em soluções nutritivas contendo 5 e $10 \mathrm{mg} /$ litro de ferro foram altos, indicando que grande parte da variabilidade encontrada na população BH-1146 x Siete Cerros, em geração $F_{2}$, foi đe origem genética, permitindo, pois, seleçôes nas primeiras geraçōes segregantes para essa característica.
\end{abstract}

Termos de indexação: tolerância à toxicidade de ferro em trigo; Siete Cerros, cultivar tolerante à toxicidade de ferro; BH-1146, cultivar sensível à toxicidade de ferro; soluções nutritivas.

$\left({ }^{1}\right)$ Com verba suplementar do Acordo do Trigo entre as Cooperativas de Produtores Rurais do Vale do Paranapanema e a Secretaria de Agricultura e Abastecimento, mediante o Instituto Agronômico. Trabalho apresentado na IX Reunião Norte-Brasileira de Pesquisa de Trigo. Brasília (DF), 10-14 de janeiro de 1983. Recebido para publicação em setembro de 1983.

$\left({ }^{2}\right)$ Seção de Arroz e Cereais de Inverno, Instituto Agronômico (IAC), Caixa Postal 28, $13100-$ Campinas (SP).

${ }^{3}$ ) Com bolsa de suplementação do $\mathrm{CNPq}$. 


\section{INTRODUÇÃO}

Uma das soluções para a presença de elevados teores de alumínio, ferro e manganês em solos ácidos, tóxicos às plantas cultivadas, seria a obtenção de cultivares portadores de tolerância genética a esses elementos.

O cultivar de trigo BH-1146 tem apresentado grande tolerância ao efeito prejudicial do alumínio em solução nutritiva e no solo, enquanto o Siete Cerros tem mostrado elevada suscetibilidade a esse elemento (CAMARGO \& OLIVEIRA, 1981). 'BH-1146' diferiu de 'Siete Cerros' por um par de genes dominantes para tolerância ao $\mathrm{Al}^{3+}$ (CAMARGO, 1981).

Em soluções nutritivas contendo elevadas concentrações de manganês, verificou-se que o 'BH-1 146' foi o mais sensivel entre os estudados e que 'Siete Cerros' apresentou-se como tolerante (CAMARGO \& OLIVEIRA, 1983). Esse comportamento inverso também foi obtido por FOY et alii (1973), que relataram reações semelhantes entre os cultivares de trigo Atlas66 (tolerante ao $\mathrm{Al}^{3+}$ e sensível ao $\mathrm{Mn}^{2+}$ ) e Monon (sensível ao $\mathrm{Al}^{3+}$ e tolerante ao $\mathrm{Mn}^{2+}$ ).

Os valores da herdabilidade em sentido amplo para tolerância a níveis tóxicos de $\mathrm{Mn}$ em solução nutritiva, estudados nas populações oriu1 das do cruzamento BH-1146 x Siete Cerros, foram altos; essa indicação de que grande parte da variabilidade encontrada foi de origem genética, sugere que seleções visando às plantas tolerantes ao $\mathrm{Mn}^{2+}$ poderiam ser efetivas a partir das gerações $F_{2}$ e $F_{3}$ (CAMARGO, 1983). CAMARGO (1983) demonstrou ser possível transferir, por meio de cruzamento entre os cultivares BH-1 146 e Siete Cerros, a tolerância ao manganês do Siete Cerros para o BH-1146 ou a tolerância ao alumínio deste ao Sie te Cerros.

Empregando soluções nutritivas contendo diferentes concentrações de ferro $(0 ; 5 ; 10 ; 20$ e $40 \mathrm{mg} /$ litro), foi possível classificar os cultivares de trigo BH-1146, IAC-18, IAC-24, IAC-5, IAC-13, IAC-17 e IRN-20463 como sensíveis e, Siete Cerros, CNT-8 e Alondra-4546, como os mais tolerantes entre os estudados (CAMARGO \& FREITAS, 1985).

O presente trabalho tem por objetivo estudar o tipo de ação gênica envolvida na expressão de tolerância à toxicidade de ferro em solução nutritiva de uma população segregante de trigo originária do cruzamento entre um cultivar tolerante e outro sensível ao ferro nessas condições.

\section{MATERIAL E MÉTODOS}

Os cultivares de trigo $\mathrm{BH}-1146\left(\mathrm{P}_{1}\right)$ e Siete Cerros $\left(\mathrm{P}_{2}\right)$, bem como o cruzamento deles resultante, em geração $F_{2}$, foram testados para 
tolerância a diferentes concentrações de ferro, empregando-se a mesma técnica usada por CAMARGO \& FREITAS (1985) e transcrita a seguir:

As sementes dos diferentes genótipos $\left(\mathrm{P}_{1}, \mathrm{P}_{2}\right.$ e $\left.\mathrm{F}_{2}\right)$ foram cuidadosamente lavadas com uma solução de hipoclorito de sódio a $10 \%$ e colocadas para germinar em caixas. de Petri por 24 horas. Após esse tempo, as radículas estavam iniciando a emergência.

Quantidades semelhantes de sementes uniformes de cada genótipo foram escolhidas e colocadas sobre a parte superior de três telas de náilon que foram adaptadas sobre três vasilhas plásticas de 8,3 litros de capacidade contendo soluçoes nutritivas, de maneira que as sementes fossem mantidas úmidas e as radículas emergentes tocassem nas soluções, tendo, pois, um pronto suprimento de nutrientes.

A composição da solução nutritiva utilizada, cujo $\mathrm{pH}$ foi ajustado para 4,0 com uma solução de $\mathrm{H}_{2} \mathrm{SO}_{4} 1 \mathrm{~N}$ era a seguinte: $\mathrm{Ca}\left(\mathrm{NO}_{3}\right)_{2} 1 \mathrm{mM}$; $\mathrm{MgSO}_{4} \quad 0,5 \mathrm{mM} ; \mathrm{KNO}_{3} \operatorname{lmM} ;\left(\mathrm{NH}_{4}\right)_{2} \mathrm{SO}_{4} 0,109 \mathrm{mM} ; \mathrm{KH}_{2} \mathrm{PO}_{4} \quad 0,125 \mathrm{mM}$; $\mathrm{MnSO}_{4} \quad 0,5 \mu \mathrm{M} ; \mathrm{CuSO}_{4} \quad 0,075 \mu \mathrm{M} ; \mathrm{ZnSO}_{4} \quad 0,2 \mu \mathrm{M} ; \mathrm{NaCl} 7,5 \mu \mathrm{M} ; \mathrm{Fe}-\mathrm{CYDTA}$ $10 \mu \mathrm{M} ; \mathrm{Na}_{2} \mathrm{MoO}_{4} \quad 0,025 \mu \mathrm{M}$ e $\mathrm{H}_{3} \mathrm{BO}_{3} 2,5 \mu \mathrm{M}$. As vasilhas plásticas contendo as soluções foram colocadas em banho-maria a $27 \pm 1^{\circ} \mathrm{C}$ dentro do laboratório e, o experimento, mantido com luz artificial durante todo o tempo.

As plantas desenvolveram-se nessas condições por 48 horas. Decorrido esse periodo, adicionou-se a cada uma das três soluções $\mathrm{FeSO}_{4} \cdot 7 \mathrm{H}_{2} \mathrm{O}$ de modo a serem obtidas as concentrações finais de 0,$56 ; 5$ e $10 \mathrm{mg} / \mathrm{litro}$ de ferro.

As plantas cresceram nas diferentes soluções de tratamento com ferro continuamente arejadas, durante dez dias, sendo seu $\mathrm{pH}$ mantido o mais próximo possível de 4,0 com ajustamentos diários.

Após dez dias, as plantas foram retiradas, determinando-se o crescimento da raiz primária central de cada plântula em milímetro.

Com os dados obtidos do comprimento das raízes dos diferentes genótipos estudados em três concentrações de ferro, foram estimados os valores da herdabilidade em sentido amplo, segundo o método de BRIGGS \& KNOWLES (1977), bem como o grau de dominância, segundo FALCONER (1960) para raízes mais compridas, mediante a seguinte fórmula:

$$
\begin{aligned}
& \mathrm{D}=\overline{\mathrm{P}}_{1}-\left(\overline{\mathrm{P}}_{1}+\overline{\mathrm{P}}_{2}\right) / 2 \\
& \mathrm{~d}_{2}=\left[\overline{\mathrm{F}}_{2}-\left(\overline{\mathrm{P}}_{1}+\overline{\mathrm{P}}_{2}\right) / 2\right] / \mathrm{D}
\end{aligned}
$$


onde: compridas;

$\underline{\mathrm{D}}=$ diferencial;

$\overline{\mathrm{P}}_{1}=$ média do comprimento da raiz do pai que exibiu raízes mais curtas;

$\overline{\mathbf{P}}_{2}=$ média do comprimento da raiz do pai que exibiu rázes mais

$\mathrm{d}_{2}=$ grau de dominância para a geração $\mathrm{F}_{2}$;

$\bar{F}_{2}=$ comprimento médio da raiz das plântulas em geração $F_{2}$.

\section{RESULTADOS E DISCUSSÃO}

O número de plantas, o comprimento médio das raizes, a variância e o coeficiente de variação das três populações $\left(\mathrm{P}_{1}, \mathrm{P}_{2}\right.$ e $\left.\mathrm{F}_{2}\right)$ estudadas em soluções nutritivas arejadas contendo três diferentes concentrações de ferro encontram-se no quadro 1 .

QUADRO 1 - Número de plantas, comprimento médio das raízes, variância, coeficiente de variação das três populações estudadas em soluções nutritivas contendo três diferentes concentraçōes de ferro.

\begin{tabular}{clcccc}
\hline $\begin{array}{c}\text { Concen- } \\
\text { traçбes } \\
\text { de Fe }\end{array}$ & \multicolumn{1}{c}{ Populaçбes } & $\begin{array}{c}\text { Plantas } \\
\text { estudadas }\end{array}$ & $\begin{array}{c}\text { Comprimento } \\
\text { médio das } \\
\text { raízes }\end{array}$ & Variância & CV \\
\hline mg/litro & & nq & mm & & $\%$ \\
0,56 & BH-1 146 $\left(\mathrm{P}_{1}\right)$ & 10 & 200,4 & 219,44 & 7,39 \\
& Siete Cerros $\left(\mathrm{P}_{2}\right)$ & 14 & 133,9 & 317,50 & 13,30 \\
& $\mathrm{P}_{1} \times \mathrm{P}_{2}\left(\mathrm{~F}_{2}\right)$ & 119 & 179,4 & 685,43 & 14,59 \\
5,00 & BH-1146 $\left(\mathrm{P}_{1}\right)$ & 12 & 84,5 & 45,25 & 7,96 \\
& Siete Cerros $\left(\mathrm{P}_{2}\right)$ & 17 & 106,7 & 309,38 & 16,48 \\
& $\mathrm{P}_{1} \times \mathrm{P}_{2}\left(\mathrm{~F}_{2}\right)$ & 121 & 123,4 & 774,91 & 22,55 \\
10,00 & BH-1 146 $\left(\mathrm{P}_{1}\right)$ & 14 & 24,4 & 33,10 & 23,58 \\
& Siete Cerros $\left(\mathrm{P}_{2}\right)$ & 16 & 89,7 & 186,59 & 15,23 \\
& $\mathrm{P}_{1} \times \mathrm{P}_{2}\left(\mathrm{~F}_{2}\right)$ & 122 & 58,8 & 574,60 & 40,77 \\
\hline
\end{tabular}

A freqüência da distribuição do comprimento da raiz primária central das plântulas dos cultivares utilizados como pais, e das plântulas da população $\mathrm{F}_{2}$, proveniente do cruzamento entre ambos está representada nas figuras 1 e 2 . 

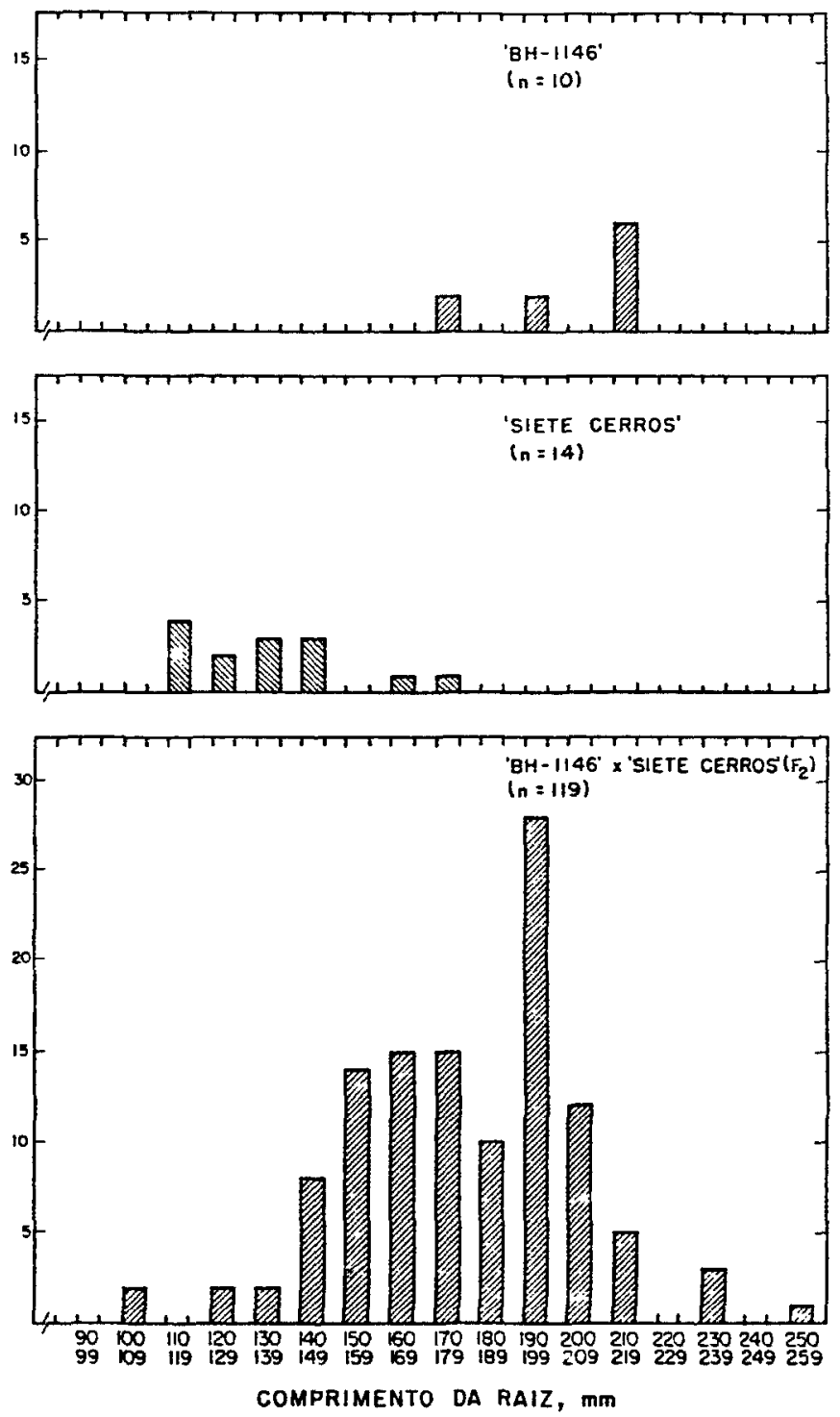

FIGURA 1 - Frequiência da distribuição do comprimento da raiz primária central das plântulas dos cultivares Siete Cerros e BH-1146, utilizados como pais, e das plântulas da população $F_{2}$, originária do cruzamento entre ambos, observada quando cultivados em solução nutritiva contendo $0,56 \mathrm{mg} /$ litro de ferro. 

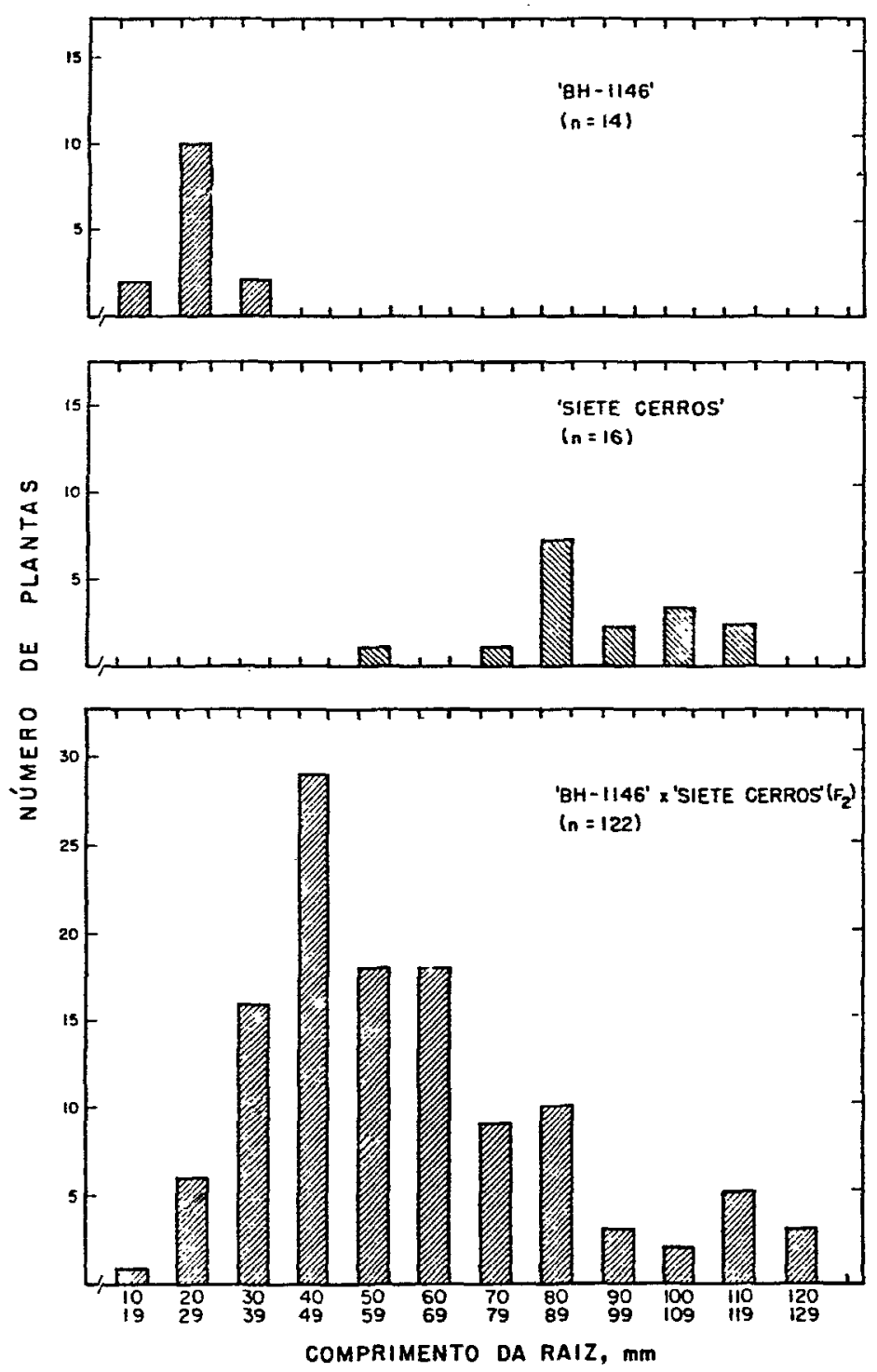

FIGURA 2 - Freqüência da distribuição do comprimento da raiz primária central das plântulas dos cultivares Siete Cerros e BH-1 146, utilizados como pais, e das plântulas da população $F_{2}$, originária do cruzamento entre ambos, observada quando cultivados em solução nutritiva contendo $10 \mathrm{mg} /$ litro de ferro. 
As diferenças nos comprimentos das raízes dos três genótipos testados em soluçðes com $0,56 \mathrm{mg} /$ litro de ferro sugerem a presença de grande variabilidade genética; nessas condiçðes; sem excesso de ferro, o cultivar BH-1146 apresentou raizes $49,7 \%$ mais compridas do que o Siete Cerros. Esses resultados estão de acordo com os obtidos por CAMARGO \& OLIVEIRA (1981) e CAMARGO (1983), onde o cultivar BH-1 146 apresentou grande potencial genético para maior crescimento das raízes em relação ao 'Siete Cerros' em ausência de estresse de alumínio e manganês.

$\mathrm{Na}$ solução nutritiva com $5 \mathrm{mg} /$ litro de ferro verificou-se uma redução de $57,8 \%$ das raizes do $\mathrm{BH}-1146$, e de $87,8 \%$ na solução de $10 \mathrm{mg} /$ litro de ferro. Esses valores demonstraram sua grande sensibilidade quando comparados com o Siete Cerros, que se apresentou tolerante aos níveis crescentes de ferro na solução, reduzindo o crescimento das raf́zes em relação ao nivel de $0,56 \mathrm{mg} /$ litro de ferro, considerado normal, de 20,3 e $33 \%$, respectivamente, quando foram adicionados 5 e $10 \mathrm{mg} / \mathrm{litro}$ de ferro.

Pela figura 3 , verifica-se que os sistemas radiculares desses cultivares, após um crescimento de dez dias em solução nutritiva arejada contendo $10 \mathrm{mg} /$ litro de ferro, apresentaram as seguintes características: BH-1146: rafzes curtas, com mau desenvolvimento e descoloramento do meristema, e Siete Cerros: raízes bem desenvolvidas, e com presença de raízes secundárias.

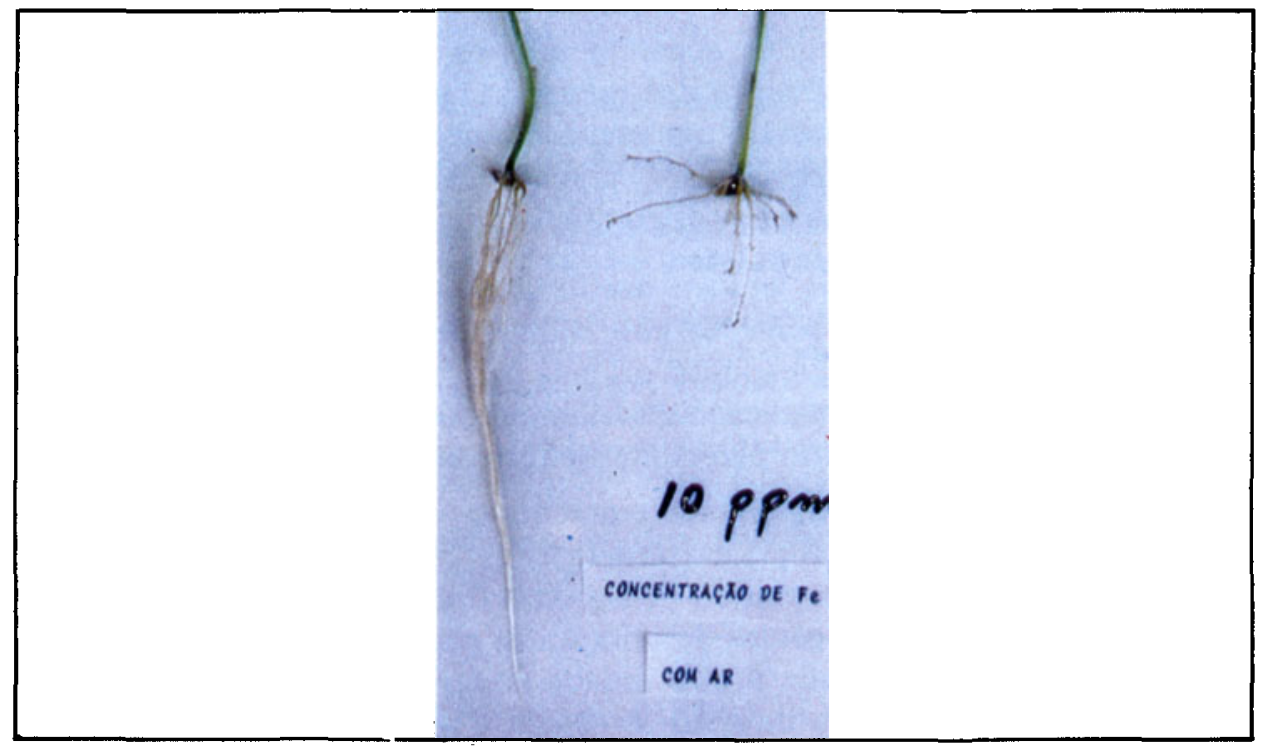

FIGURA 3 - Sistema radicular dos cultivares Siete Cerros e BH-1146, após dez dias de crescimento em solução nutritiva arejada contendo $10 \mathrm{mg} /$ litro de ferro. 
A herdabilidade em sentido amplo e o grau de dominância calculados para comprimento das rázes nos níveis de 0,$56 ; 5 \mathrm{e} 10 \mathrm{mg} /$ litro de ferro nas soluçðes nutritivas, utilizando os dados para a população $F_{2}$ do cruzamento BH-1146 x. Siete Cerros, bem como para os pais, encontram-se no quadro 2.

QUADRO 2 - Herdabilidade em sentido amplo $(\mathrm{H})$ e grau de dominância (d) calculados para comprimento médio das raízes primárias centrais de trigo cultivado em soluçoes nutritivas contendo três diferentes concentraçōes de ferro

Concentraçoes de Fe $\quad \mathrm{H}^{(1)} \quad \mathrm{d}^{(2)}$

$\mathrm{mg} /$ litro

$\begin{array}{rcc}0,56 & 0,608 & +0,368 \\ 5,00 & 0,771 & - \\ 10,00 & 0,809 & +0,054\end{array}$

( $\left.{ }^{1}\right) \mathrm{H}=\left\{\operatorname{Var} \mathrm{F}_{2}-\left[\left(\operatorname{Var} \mathrm{P}_{1}+\operatorname{Var} \mathrm{P}_{2}\right) / 2\right]\right\} / \operatorname{Var} \mathrm{F}_{2}$

$\left({ }^{2}\right)$ Grau de dominância igual a +1 significa dominância completa dos genes que condicionam raizes compridas $e,-1$, dominância completa dos genes que condicionam raízes curtas.

Os resultados obtidos sugerem que os genes que condicionaram maior capacidade de crescimento das raízes do cultivar BH-1146, em ausência do estresse de ferro, tiveram um comportamento parcialmente dominante, enquanto os que condicionaram a característica raízes em menor comprimento no Siete Cerros, nas mesmas condiçбes, exibiram um comportamento parcialmente recessivo a esse caráter.

Considerando as soluçбes contendo $10 \mathrm{mg} /$ litro de ferro, os genes existentes no Siete Cerros, responsáveis pela tolerância à toxicidade de ferro, apresentaram um comportamento parcialmente dominante, e os genes do BH-1146 um comportamento parcialmente recessivo.

Os valores da herdabilidade em sentido amplo para o comprimento das raízes, empregando 0,$56 ; 5$ e $10 \mathrm{mg} /$ litro de ferro nas soluçðes nutritivas foram considerados altos, variando de 0,608 a 0,809 . Com esses valores, poderia ser esperada, em progênies de uma unica planta, na geração $F_{2}$ do cruzamento considerado, grande probabilidade de repetição do comportamento ou característica da planta da qual se originou. Desse modo, seria possível transferir a característica maior comprimento da raiz do ' $\mathrm{BH}-1146$ ' ao 'Siete Cerros', em ausência do estresse de ferro, e a tolerância à toxicidade de ferro do 'Siete Cerros' ao 'BH-1146'. 
Os resultados indicaram que a concentração de $10 \mathrm{mg} /$ litro de $\mathrm{Fe}^{2+}$ na solução tratamento foi adequada para a separação visual das plantas tolerantes e sensíveis baseada no comprimento da raiz após dez dias de crescimento nessa solução, visando a um programa de melhoramento genético para a tolerância à toxicidade de ferro.

\section{CONCLUSOES}

1. Observou-se dominância parcial para tolerância à toxicidade causada pela presença de $10 \mathrm{mg} /$ litro de ferro na solução nutritiva, pelo crescimento da raiz envolvendo cruzamento entre o cultivar tolerante Siete Cerros e o sensível BH-1146.

2. Os altos valores da herdabilidade em sentido amplo para a tolerância à toxicidade de ferro, expressa na capacidade de crescimento das rafzes das plântulas de trigo em soluçðes nutritivas contendo 5 e $10 \mathrm{mg} / \mathrm{litro}$ de ferro, indicam que grande parte da variabilidade encontrada na população $\mathrm{BH}-1146$ x Siete Cerros, em geração $\mathrm{F}_{2}$, foi de origem genética, permitindo, pois, seleçðes nas primeiras geraçðes segregantes para essa característica.

\section{SUMMARY}

\section{GENETIC STUDIES OF TOLERANCE TO IRON TOXICITY IN WHEAT}

The cultivar Siete Cerros with tolerance to iron toxicity and the cultivar BH-1146 showing sensitivity to iron, were crossed. Parents and seeds $F_{2}$ of this cross were cultivated in aerated nutrient solutions containing $0.56,5$ and $10 \mathrm{mg} / \mathrm{l}$ of iron, under constant temperature $\left(27 \pm 1^{\circ} \mathrm{C}\right)$ and $\mathrm{pH} 4.0$. The length of the central primary root of each genotype under study after ten days being cultivated in nutrient solutions containing different iron concentration was used to evaluate the levels of tolerance to this element. It was observed partial dominance for iron tolerance considering the studied $F_{2}$ population. Broad sense heritability estimates were high for iron tolerance expressed by root growth capacity in nutrient solutions with 5 and $10 \mathrm{mg} / 1$ of iron. These results suggested that great part of the total variation found in the studied $\mathrm{F}_{2}$ population for this characteristc was of genetic origin. So, selection for iron tolerance would be effective in early segregating generations from the cross envolving a tolerant and a sensitive cultivar.

Index terms: wheat tolerance to iron toxicity, Siete Cerros, tolerant cultivar and BH1146 , sensitive cultivar; nutrient solutions.

\section{REFERÊNCIAS BIBLIOGRÁFICAS}

BRIGGS, F. N. \& KNOWLES, P. F. Introduction to plant breeding. Davis, Reinhold Publishing Corporation, 1977. 426p. 
CAMARGO, C. E. O. Melhoramento do trigo. I. Hereditariedade da tolerância à toxicidade do alumínio. Bragantia, Campinas, 40:33-45, 1981.

Melhoramento do trigo. III. Evidência de controle genético na tolerância ao manganês tóxico em trigo. Bragantia, Campinas, 42:91-103, 1983.

\& FREITAS, J. G. Tolerância de cultivares de trigo a diferentes níveis de ferro em solução nutritiva. Bragantia, Campinas, 44(1):65-75, 1985.

\& OLIVIERA, O. F. Tolerância de cultivares de trigo a diferentes níveis de alumínio em soluçao nutritiva e no solo. Bragantia, Campinas, 40:21-31, 1981.

$\&$

Tolerância de cultivares de trigo a diferentes níveis de manganês em solução nutritiva. Bragantia, Campinas, 42:65-78, 1983.

FALCONER, D. S. Introduction to quantitative genetics. New York, Ronald Press, 1960. 365p.

FOY, C. D.; FLEMING, A. L. \& SCHWARTZ, J. W. Oposite aluminum and manganese tolerances of two wheat varieties. Agronomy Journal, 65: 123-126, 1973. 